\title{
DISTRIBUTION PATTERNS AND CERCARIAL SHEDDING OF BULINUS NASUTUS AND OTHER SNAILS IN THE MSAMBWENI AREA, COAST PROVINCE, KENYA
}

\author{
H. CURTIS KARIUKI, JULIE A. CLENNON, MELINDA S. BRADY, URIEL KITRON, ROBERT F. STURROCK, \\ JOHN H. OUMA, SAIDI TOSHA MALICK NDZOVU, PETER MUNGAI, ORIT HOFFMAN, JOSEPH HAMBURGER, \\ CARA PELLEGRINI, ERIC M. MUCHIRI, AND CHARLES H. KING \\ Division of Vector Borne Diseases, Ministry of Health, Nairobi, Kenya; Division of Epidemiology and Preventive Medicine, \\ Department of Veterinary Pathobiology, University of Illinois, Urbana, Illinois; London School of Hygiene and Tropical Medicine, \\ London, United Kingdom; Kenya Medical Research Institute, Nairobi, Kenya; Helminthology Unit, Hadassah Medical School, \\ Hebrew University of Jerusalem, Israel; University of Pennsylvania School of Medicine, Philadelphia, Pennsylvania; Center for \\ Global Health and Diseases, Case Western Reserve University School of Medicine, Cleveland, Ohio
}

\begin{abstract}
In the Msambweni area of the Kwale District in Kenya, an area endemic for Schistosoma haematobium, potential intermediate-host snails were systematically surveyed in water bodies associated with human contact that were previously surveyed in the 1980s. Bulinus (africanus) nasutus, which accounted for $67 \%$ of the snails collected, was the only snail shedding S. haematobium cercariae. Lanistes purpureus was the second most common snail (25\%); lower numbers of Bulinus forskalii and Melanoides tuberculata were also recovered. Infection with non-S. haematobium trematodes was found among all snail species. Rainfall was significantly associated with the temporal distribution of all snail species: high numbers of Bulinus nasutus developed after extensive rainfall, followed, in turn, by increased $S$. haematobium shedding. Spatial distribution of snails was significantly clustered over a range of up to $1 \mathrm{~km}$, with peak clustering observed at a distance of 400 meters. Water lily (Nymphaea spp.) and several aquatic grass species appeared necessary for local colonization by B. nasutus or L. purpureus.
\end{abstract}

\section{INTRODUCTION}

Urinary schistosomiasis due to Schistosoma haematobium is common in most areas of Coast Province, Kenya, where infection prevalence ranges from $25 \%$ to more than $90 \%$ (Muchiri EM, unpublished data, Clennon JA and others, unpublished data). ${ }^{1-4}$ Prevalence among schoolchildren in the Kwale District is typically $57-90 \%$, with prevalence in the present study area, the Msambweni Division, of up to $78 \%{ }^{5}$ In contrast, there is no transmission of S. mansoni in Msambweni, and the intestinal form of schistosomiasis is absent from a region extending $100 \mathrm{~km}$ inland from the coast. The absence of $S$. mansoni is attributable to the absence of the Biomphalaria spp. intermediate-host snails from most of Coast Province, apart from the inland district of TaitaTaveta. $^{6,7}$ Sturrock $^{8}$ has suggested that high constant temperatures, among other limiting factors, ${ }^{9}$ may account for the failure for Biomphalaria to establish in this area. However, the $S$. haematobium intermediate hosts of the Bulinus (africanus) group species, which are more tolerant of high temperatures, are well represented here.

In Kenya, the $B$. africanus group of snails is represented by B. (africanus) globosus, B. (a.) africanus, B.(a.) nasutus, and $B$. (a.) ugandae. All, apart from $B$. (a.) ugandae, are important hosts of $S$. haematobium in Kenya. ${ }^{10,11}$ The distribution of $B$. (a.) globosus and B. (a.) nasutus overlaps in Coastal Kenya and in the Lake Victoria area. Bulinus (a.) africanus is commonly found in higher altitude areas of eastern and central Kenya. Bulinus (a.) ugandae is distributed in limited foci in the Lake Victoria area. ${ }^{12}$ In the Coast Province of Kenya, B. globosus and B. nasutus can be found occupying a wide diversity of habitats such as quarry pits, streams, drainage canals, dams, and seasonal pools. ${ }^{13}$ In the Msambweni area, the focus of the present study, transmission of S. haematobium occurs most frequently in small freshwater impoundments, which may dry for varying periods, depending on rainfall. Remarkably, in contrast to the high human prevalence of $S$. haematobium infection in Msambweni, the proportion of snails shedding $S$. haematobium cercariae has been previously detected to be only $0.5-1.2 \%{ }^{14}$

To understand how an area with such a low percentage of snails shedding S. haematobium cercariae could coincide with high human infection prevalence, we characterized the snail population patterns within the area and examined their overlap with human infection patterns. Because snail populations are highly variable temporally, it was also essential to consider both seasonal and spatial trends for factors associated with the presence and density of $S$. haematobium intermediate-host species, and the snail species that compete with them. ${ }^{15}$ This report describes the distribution and seasonal fluctuation of the intermediate host snail (B. nasutus) and other snails sharing the same aquatic habitats in Msambweni area. (Similar snail studies were performed some 20 years ago in this same area, ${ }^{14}$ allowing comparison with the present study.) The spatial and temporal patterns were analyzed and associated with rainfall and environmental determinants as part of a comprehensive study of transmission of S. haematobium in 10 villages. With a companion paper, ${ }^{16}$ we apply novel mapping and statistical tools to analyze the patterns of local snail and human infection.

\section{MATERIAL AND METHODS}

Study area. Msambweni Division is situated in the Kwale District of Coast Province, approximately $50 \mathrm{~km}$ south of Mombasa, Kenya. The $25-\mathrm{km}^{2}$ research area is centered at the geographic coordinates $4.46^{\circ} \mathrm{S}$ and $39.45^{\circ} \mathrm{E}$ (Figure 1) and has been previously described in detail. ${ }^{5,14,17}$ The area has a monsoon-type climate, with the period of January to April-May being hot and dry. The mean monthly temperature varies from $26.3^{\circ} \mathrm{C} 26.6^{\circ} \mathrm{C}$, with lows of $23.5^{\circ} \mathrm{C}$ (July) to $26.9^{\circ} \mathrm{C}$ (March-April) and highs from $26.7^{\circ} \mathrm{C}$ (August) to $36.3^{\circ} \mathrm{C}$ (February). Annual precipitation varies from $900 \mathrm{~mm}$ to 1,500 $\mathrm{mm}$, with large yearly and monthly fluctuations. There are usually two rainy seasons, the long rains starting around March and continuing until July, and the short rains beginning in October and lasting through November. Monthly rainfall records for the study period were obtained from the di- 


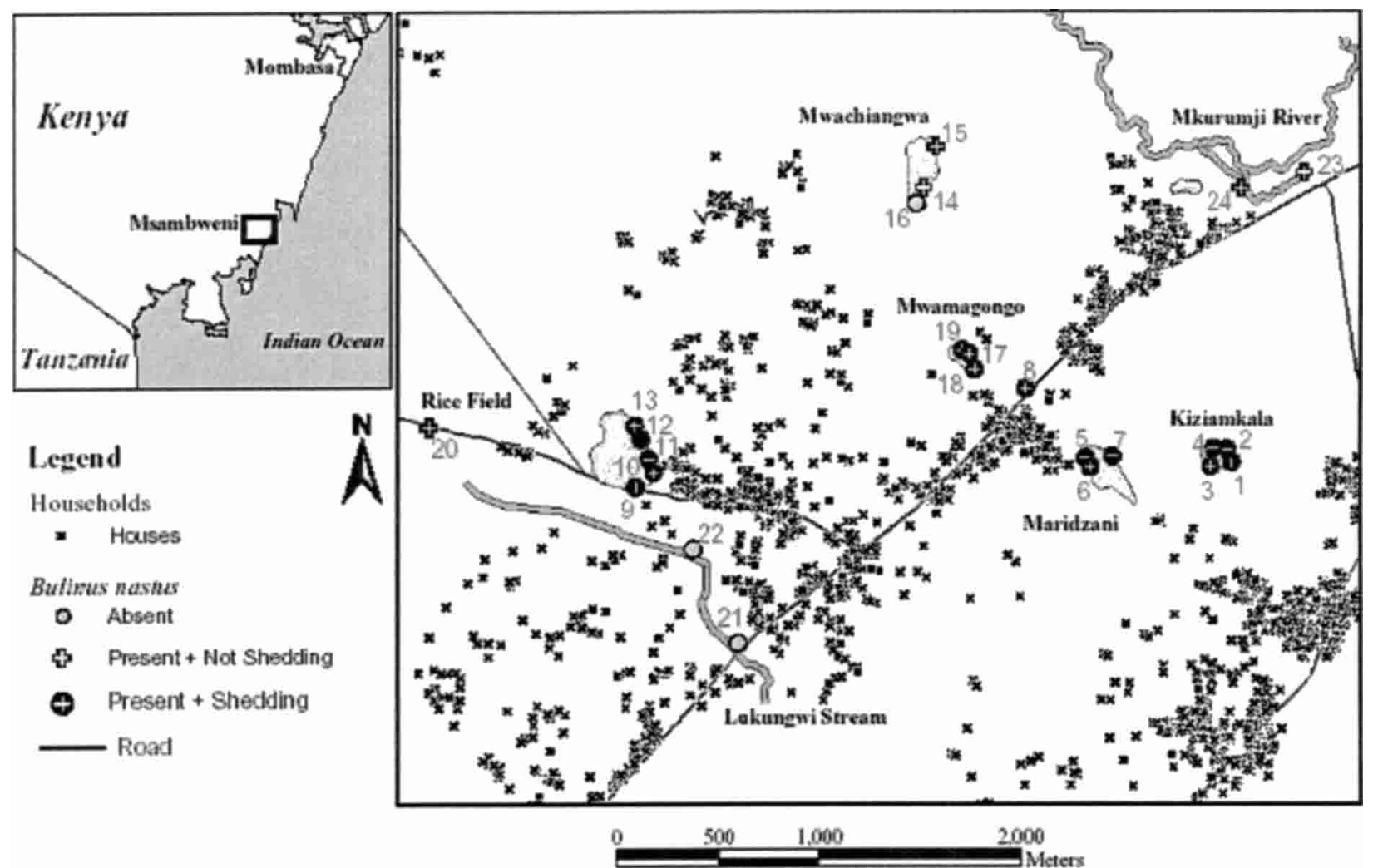

FIGURE 1. Snail collection sites, presence of Bulinus nasutus, and shedding of Schistosoma haematobium cercariae in Msambweni, Kenya, 2001-2003. The inset shows the location of study area in coastal Kenya.

visional agriculture offices situated near the Msambweni hospital.

A perennial river (the Mkurumji River) and a seasonal stream (the Lukungwi Stream), flow through the area. ${ }^{14} \mathrm{Sev}$ eral rain-filled ponds are located in proximity to the 10 villages included in this study, but most of the pools dry out completely during periods of prolonged drought. When they contain water, these pools harbor various snail species, including $B$. nasutus, one of the intermediate hosts of $S$. haematobium in Kenya. ${ }^{14}$ Subsistence rice cultivation close to the water bodies is widely carried out. Maize, cassava, sweet potatoes, and other crops are planted in the general area for domestic consumption. Livestock (cattle and goats) is also kept.

The present study was conducted between March 1984 and July 1987, in addition to February 2001 and May 2003, around nine water bodies: six rain-filled ponds, one rice field, two sites along the banks of the Mkurumji River, and two sites on the seasonal Lukungwi Stream (Figure 1). A total of 24 sites were monitored with up to five snail sampling sites selected per pond based on human water contact activity. The water bodies studied were Kiziamkala pond, with four sites (1-4); Maridzani pond, with three sites (5-7); Bovo pond (site number 8); Nimbodze pond, with five sites (9-13); Mwachiangwa pond, with three sites (14-16); Mwamagongo pond, with three sites (17-19); a rice field, (site 20); Mkurumji River, with two sites (21 and 22) and Lukungwi Stream, with two sites (23 and 24) (Figure 1).

The major water contact activities included doing laundry, bathing, and swimming, and for young children fishing and playing. Although some alternative water sources (wells, boreholes, piped water stands, and water kiosks) are available, residents appeared to prefer the customary water contact points at the pools where, due to the hot weather conditions for most of the year, they can also bathe and/or swim (Clennon JA and others, unpublished data). ${ }^{17}$

Ethical oversight. After obtaining informed consent from area residents (or for children from their parents), human infection status and water use activities were monitored under human investigations protocols reviewed and approved by the Ethical Review Board of the Kenya Medical Research Institute (Nairobi, Kenya) and by the Human Investigations Review Board of University Hospitals of Cleveland, Ohio.

Snail sampling. Snail sampling was conducted by one man searching each site for five minutes using a standard flat wiremesh scoop with a mesh size of $2 \mathrm{~mm} .{ }^{18}$ Snails were taken to the laboratory at Msambweni Hospital, separated by species, and tested for cercarial shedding. Species confirmation for $B$. nasutus was carried out by genetic mapping ${ }^{19}$ at the Natural History Museum (London, London, United Kingdom) and at Hebrew University (Jerusalem, Israel) (Hamburger J, Hoffman $\mathrm{O}$, unpublished data). The snails were placed individually in flat-bottomed glass vials (height $=7.5 \mathrm{~cm}$, Diameter $=$ $2.5 \mathrm{~cm}$ ) containing clear, filtered, pond water and exposed to indirect sunlight for a maximum duration of four hours. Snails that did not shed cercariae on the first exposure were reexposed on the second day. Cercariae were categorized either as those of $S$. haematobium or those of other trematodes (non-S. haematobium cercariae), as described by Frandsen and Christensen. ${ }^{20}$ 
Other parameters recorded at each site during every snail collection were water temperature (at a depth of $15 \mathrm{~cm}$ ), water $\mathrm{pH}$ and conductivity (Oakton portable meters; Fisher Scientific, Pittsburgh, PA), turbidity (visual scale), site condition (dry or having water), water level, and the presence or absence of vegetation such as water lilies (Nymphaea spp.), sedge (Cyperus exaltatus Retz). or various species of grass.

Mapping and statistical analysis. All snail collection sites were located using a global positioning system (GPS) (GeoExplorer II; Trimble, Sunnyvale, CA) and identified on an Ikonos (Space Imaging, Atlanta, GA) satellite image acquired on March 4, 2001 at 7:45 AM. The $25-\mathrm{km}^{2}$ study area is centered around $4.464^{\circ} \mathrm{S}$ and $39.449^{\circ} \mathrm{E}$.

The image and GPS readings were imported into ArcView version 3.3 and ArcGIS version 8.3 (Environmental Systems Research Institute, Redlands, CA). Statistical spatial analyses were conducted using point pattern analysis. ${ }^{21}$ Specifically, we used a weighted K-function (second-order analysis) to detect global clustering, ${ }^{22,23}$ and the Getis and $\mathrm{Ord}^{24} \mathrm{Gi}^{*}(\mathrm{~d})$ statistic to detect local clustering of snails and cercarial shedding. (For details on the mapping and spatial statistic analysis, see Clennon and others. ${ }^{16}$ )

Correlation, homogeneity chi-square (continuity adjusted), analysis of variance, and linear regression analyses were conducted using SPSS version 11.5.0 (SPSS, Inc., Chicago, IL).

\section{RESULTS}

Diversity and spatial distribution of snails. Three species of snails, B. nasutus, Lanistes purpureus, and B. forskalii, were common in the study area, and were found in eight, seven, and six of the nine water bodies, respectively. Two other snail species were also recovered: Melanoides tuberculata was found in two water bodies, and Pila ovata was found only occasionally at the rice field and in the connected Lukungwi Stream (Table 1). Bulinus nasutus, the intermediate host for $S$. haematobium in this study area, was the most common snail, accounting for more than two-thirds of all snails collected, with L. purpureus accounting for most of the rest $(25 \%)$ of all snails.

Bulinus nasutus was found in all water bodies except the Mkurumji River; although it was rare in Mwachiangwa pond, it was common in Nimbodze, Mwamagongo, Maridzani, and Kiziamkala ponds. Lanistes purpureus was found in all water bodies, except for the Mkurumji River and Kiziamkala pond,

TABLE 1

Distribution of snails among water bodies in Msambweni, Kenya, February 2001-May 2003

\begin{tabular}{lrrrrr}
\hline \multicolumn{1}{c}{ Water body } & $\begin{array}{c}\text { Bulinus } \\
\text { nasutus }\end{array}$ & $\begin{array}{c}\text { Lanistes } \\
\text { purpureus }\end{array}$ & $\begin{array}{c}\text { Bulinus } \\
\text { forskalii }\end{array}$ & $\begin{array}{c}\text { Melanoides } \\
\text { tuberculata }\end{array}$ & Total \\
\hline Kiziamkala & 1,697 & 0 & 389 & 0 & 2,086 \\
Maridzani & 1,750 & 186 & 491 & 198 & 2,625 \\
Bovo & 1,127 & 833 & 0 & 0 & 1,960 \\
Nimbodze & 2,929 & 1,153 & 96 & 0 & 4,178 \\
Mwachiamangwa & 2 & 117 & 28 & 1 & 148 \\
Mwamagongo & 2,752 & 1,568 & 10 & 0 & 4,330 \\
Rice field & 68 & 92 & 1 & 0 & 776 \\
Mkurumji & 0 & 0 & 0 & 79 & 79 \\
Lukungwi & 59 & 95 & 1 & 1 & 156 \\
Total & 11,000 & 4,044 & 1,016 & 279 & 16,339 \\
\hline
\end{tabular}

and was most common in Mwamagongo, Nimbodze, and Bovo ponds. Bulinus forskalii was most common in $\mathrm{Ki}-$ ziamkala and Maridzani (Table 1). Only at Maridzani was there complete species overlap (i.e., more than a single specimen of each of the four common snail species found). In the Mkurumji River, only $M$. tuberculata was found.

Spatial statistical analysis of the distribution of B. nasutus in the study area, using a weighted $\mathrm{K}$-function, demonstrated significant clustering of snails through distances of less than 1 $\mathrm{km}$, with peak clustering at a distance of 400 meters. This is less than the distance between any two ponds, indicating that the clustering effect is in force around individual ponds. The global statistical result was supported by the subsequent application of $\mathrm{Gi}^{*}(\mathrm{~d})$ testing to detect local clustering. Gi*(d) was $>3.0(P<0.01)$ for all Nimbodze pond sites, but not significant for any other sites. This implies that the observed global clustering effect noted for $B$. nasutus snails was primarily due to the high numbers of snails found in the five collection sites of Nimbodze pond.

Cercarial shedding. Only B. nasutus snails were found to shed $S$. haematobium cercariae, and the percentage of shedding snails within the ponds ranged from $0.2 \%$ in Bovo pond to $2.5 \%$ in Nimbodze pond (Table 2). Overall, $1.2 \%$ of the $B$. nasutus recovered in the Msambweni area shed $S$. haematobium cercariae. Nimbodze pond accounted for $73(60 \%)$ of the 122 S. haematobium cercariae shedders. In contrast, $9.1 \%$ of B. nasutus, $0.7 \%$ of L. purpureus, $3.9 \%$ of B. forskalii, and $9.5 \%$ of $M$. tuberculata shed other, non-S. haematobium cercariae, with $B$. nasutus accounting for more than $90 \%$ of non$S$. haematobium cercariae shedders within all ponds (Table 2). As for the shedding of $S$. haematobium cercariae, most of the snails shedding non-S. haematobium cercariae were collected from Nimbodze pond.

Snail density did not vary from site to site within individual ponds ( $\mathrm{F}<1.7, P>0.16$ for all ponds). The two running-water bodies, the Lukungwi Stream and the Mkurumji River, also showed no significant site-to-site variation in snail numbers $(\mathrm{t}$ $=0.23, P>0.5$ and $\mathrm{t}=-0.24, P>0.5$, respectively). Shedding prevalence for $S$. haematobium cercariae did not significantly differ among the different collection sites at Maridzani pond $(P>0.5$, by Fisher's exact test) or at Nimbodze pond $(P>0.4$, by Fisher's exact test). At Kiziamkala pond, $B$. nasutus shedding $S$. haematobium cercariae were primarily collected at site $1(P<0.05$, by Fisher's exact test). Data from Mwamagongo pond showed a strong difference between collection sites in terms of shedding prevalence: $86 \%$ of the S. haematobium

TABLE 2

Number (percent) of snails per pool shedding Schistosoma haematobium cercariae and non-S. haematobium cercariae in ponds in Msambweni, Kenya, February 2001-May 2003

\begin{tabular}{|c|c|c|c|c|c|}
\hline \multirow[b]{2}{*}{ Water body } & \multirow{2}{*}{$\begin{array}{c}S . \\
\text { haematobium } \\
\text { cercariae } \\
\text { Bulinus } \\
\text { nasutus }\end{array}$} & \multicolumn{4}{|c|}{ Non-S. haematobium cercariae } \\
\hline & & $\begin{array}{l}\text { Bulinus } \\
\text { nasutus }\end{array}$ & $\begin{array}{l}\text { Lanistes } \\
\text { purpureus }\end{array}$ & $\begin{array}{l}\text { Bulinus } \\
\text { forskalii }\end{array}$ & $\begin{array}{l}\text { Melanoides } \\
\text { tuberculata }\end{array}$ \\
\hline Kiziamkala & $16(0.9)$ & $74(4.4)$ & 0 & $15(3.9)$ & 0 \\
\hline Maridzani & $9(0.5)$ & $124(7.1)$ & $4(2.3)$ & $16(3.3)$ & $19(9.6)$ \\
\hline Bovo & $2(0.2)$ & $30(2.7)$ & 0 & 0 & 0 \\
\hline Nimbodze & $73(2.5)$ & $552(18.8)$ & $24(2.1)$ & $9(9.4)$ & 0 \\
\hline Mwamagongo & $22(0.8)$ & $151(5.5)$ & 0 & 0 & 0 \\
\hline Total & $122(1.2)$ & $931(9.1)$ & $28(0.7)$ & $40(3.9)$ & $19(9.5)$ \\
\hline
\end{tabular}


cercariae shedders in this pond were collected at site $17(P<$ 0.001 , by Fisher's exact test). In fact, site 17 showed anomalous high numbers of $S$. haematobium shedders in general (Table 3); only Nimbodze pond was comparable in terms of overall numbers of $B$. nasutus shedding $S$. haematobium cercariae. Analysis of environmental variables, including $\mathrm{pH}$, water temperature, and water conductivity, indicated no obvious differences between site 17 and the two other sites at Mwamagongo that would explain this difference in shedding prevalence for S. haematobium cercariae. However, our observations did show that site 17 was the most intensely used human water contact site of the three Mwamagongo locations (Clennon JA and others, unpublished data).

Neither Kiziamkala pond nor Nimbodze pond showed any significant site-to-site variation in non-S. haematobium cercarial shedding $\left(\chi^{2}=5.43, P>0.1\right.$ and $\chi^{2}=7.83, P>0.1$, respectively). However, site 7 at Maridzani had two months of high shedding prevalence in June and July of 2001, making its overall prevalence significantly higher than that of the other Maridzani sites $\left(\chi^{2}=15.9, P<0.01\right)$. At Mwamagongo, site 17 had significantly fewer non-S. haematobium cercariae $\left(\chi^{2}\right.$ $=15.9, P<0.0001)$. However, when examined more closely, this pattern resulted from very high numbers of uninfected $B$. nasutus collected at the site during July-August 2001. When the data from September 2001 were analyzed, the time when most non-S. haematobium cercariae from Mwamagongo were collected, no significant relationship between the Mwamagongo site and number of non-S. haematobium shedders was found $\left(\chi^{2}=1.86, P>0.3\right)$.

Seasonal patterns of snail density. For our study sites, variation in snail density over time followed the changes in water level due to seasonal and inter-annual rainfall fluctuation (Figure 2). The highest snail density was observed between July and November, with a peak in SeptemberOctober 2001, but since February 2002, snail populations have remained low.

Since these rain-filled pools are the main snail habitats, rainfall was a major contributing factor in the distribution and occurrence of snails. During the long rainy season in 2001, 366 $\mathrm{mm}$ of rainfall were recorded in April, followed by $568 \mathrm{~mm}$ in May. The short rains expected in October-November failed, resulting in the drying up of most habitats. Subsequently, the long rains in 2002 did not fall with the same intensity as in 2001; the highest peak in April was only $274 \mathrm{~mm}$. This rainfall amount was not sufficient to fill the ponds.

In 2001, all study ponds contained water throughout the year, except for Bovo and Mwamagongo, which were dry from February to April and again from November to December. However, in 2002, with the lack of rains, most ponds dried out. Maridzani pond was the only pond that contained

TABLE 3

Snail collection totals for sites in Nimbodze and Mwamagongo, Kenya ponds for the period July-October 2001

\begin{tabular}{|c|c|c|c|c|c|c|c|c|}
\hline & \multicolumn{5}{|c|}{ Nimbodze sites } & \multicolumn{3}{|c|}{ Mwamagongo sites } \\
\hline & 9 & 10 & 11 & 12 & 13 & 17 & 18 & 19 \\
\hline July & 37 & 61 & 153 & 82 & 102 & 546 & 127 & 35 \\
\hline August & 50 & 67 & 141 & 65 & 90 & 670 & 300 & 138 \\
\hline September & 128 & 152 & 269 & 160 & 244 & 731 & 1,044 & 602 \\
\hline October & 74 & 102 & 200 & 184 & 199 & 5 & 5 & 13 \\
\hline
\end{tabular}
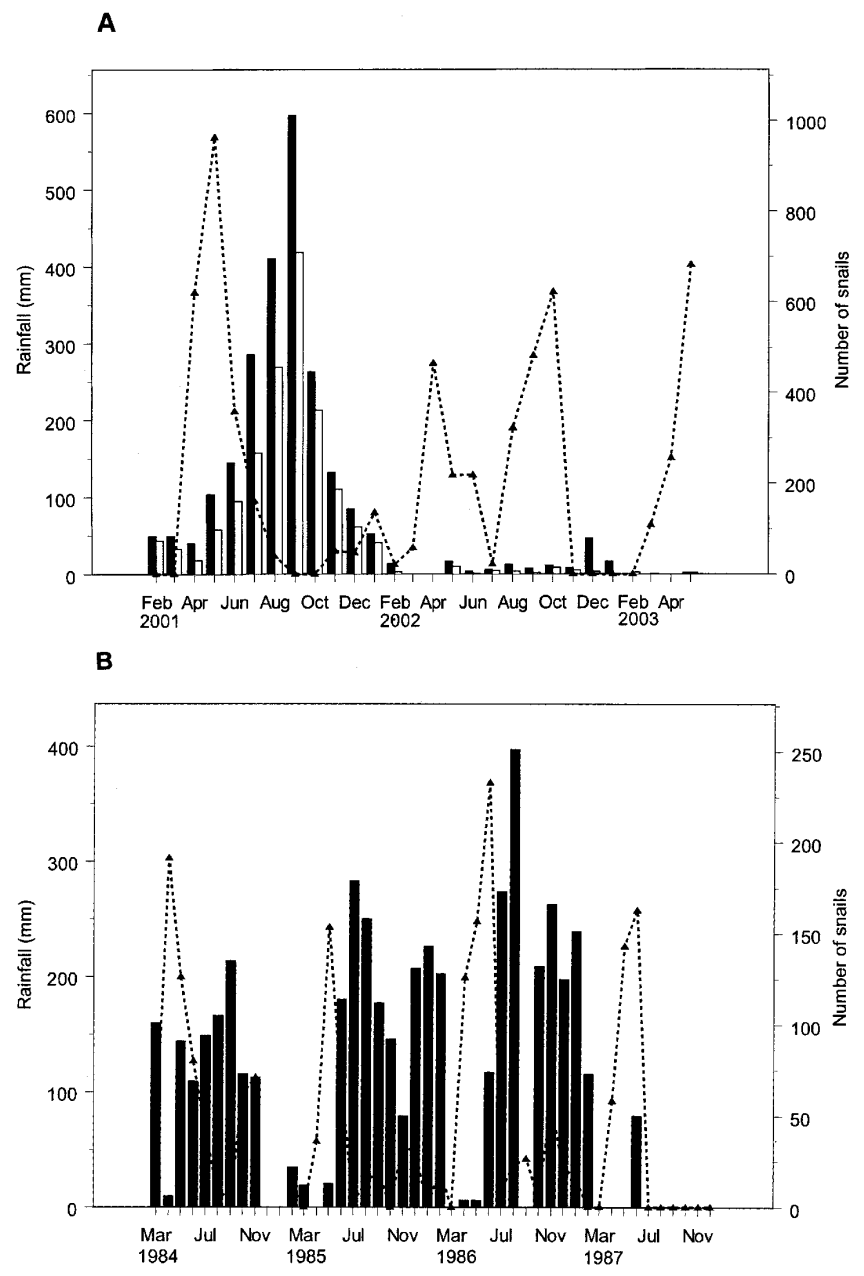

FIGURE 2. Rainfall and weekly averages for the number of snails overall, and for Bulinus nasutus only, for all collection sites in the Msambweni, Kenya study area. A, February 2001-May 2003. B, March 1984-July 1987 (B. nasutus only) ${ }^{14}$ Solid bars = all snails; open bars $=B$. nasutus; $\boldsymbol{\Delta}=$ rainfall.

water at least at one site throughout the two-year duration of this study. As of May 2003, Mwamagongo has been dry since November 2001 (19 months), Nimbodze since March 2002 (15 months), Kiziamkala since October 2002 (7 months), and Mwachiangwa since November 2002 (6 months). In comparison, for a period with more consistent rainfall, the data for $B$. nasutus and rainfall in Msambweni during 1984-1987 ${ }^{14}$ are shown in Figure 2B.

Overall, no significant relationship between rainfall and snail numbers was found when the complete 2001-2003 data were used. This result is not surprising since most of the sites experienced significant periods of complete dryness between March 2002 and May 2003, and no snails were recovered at these sites during this period. However, for the initial 2001-2002 period alone, when rainfall was correlated with snail density, a significant four-month lag in the snail population response to rainfall was found. Factoring in the fourmonth lag produced a significant relationship between total snail numbers and total rainfall $(\mathrm{r}=0.90, P<0.0001)$. In comparison, data collected in the same area between 1984 and $1987^{14}$ showed a significant relationship between snail density and total rainfall with only a two-month lag $(r=0.43$, 
$P<0.01)$. This discrepancy between the two time-lag periods is likely due to the more consistent level of rainfall that the region experienced during the mid-1980s, and indicates that longer-term precipitation patterns affect the relationship between the peak rainfall and peak snail populations in any given year.

Although snail density did not vary from site-to-site within individual ponds, there was significant variation between ponds in the timing and magnitude of peak snail populations (Table 3). Mwamagongo, which had the highest total number of snails, produced large numbers of snails only during July, August, and September 2001 before drying in October-November 2001. In contrast, Nimbodze, the pond with the next highest total, produced large numbers of snails from July 2001 through January 2002. Site 17 at Mwamagongo was particularly productive, with more than 500 snails collected at the site during each of its peak months. Most of the other ponds also had peak snail populations during the summer of 2001, although the duration of high snail populations varied for each water body: Kiziamkala, August to November; Bovo, only in August and September; and Maridzani, which appears to be more resistant to drying than the other sites, showing a slightly different pattern, a small peak in February-March of 2001 and then a longer period with high populations May to October. Interestingly, the population of M. tuberculata in Maridzani peaked from December 2001 to February 2002, long after the population peaks of B. nasutus and L. purpureus.

The cercarial shedding pattern followed the temporal changes in snail density (Figure 3); the correlation was positive and highly significant $(\mathrm{r}=0.64, P<0.0001$, by $\log$ transformed data). The pattern of non-S. haematobium cercariae shedding by $B$. nasutus also closely followed that of $S$. haematobium cercariae shedding over time (Figure 3 ).

Figure 4 shows a contour map of the numbers of $S$. haematobium cercariae-shedding snails by location over the first 13 months of observation, before most sites went dry. The observed patterns in the abundance of shedding snails indicates a strong pool-specific and seasonal variation in transmission

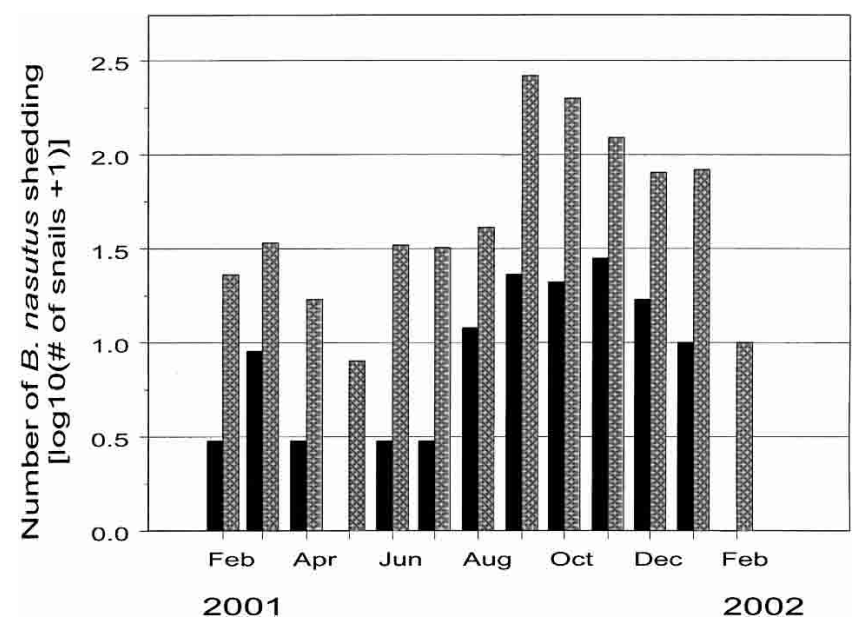

FIGURE 3. Number (log-transformed) of Bulinus nasutus snails shedding Schistosoma haematobium and non-S. haematobium cercariae each month in Msambweni, Kenya from February 2001February 2002. Hatched bars $=$ shedding non-S. haematobium cercariae; solid bars $=$ shedding $S$. haematobium cercariae.

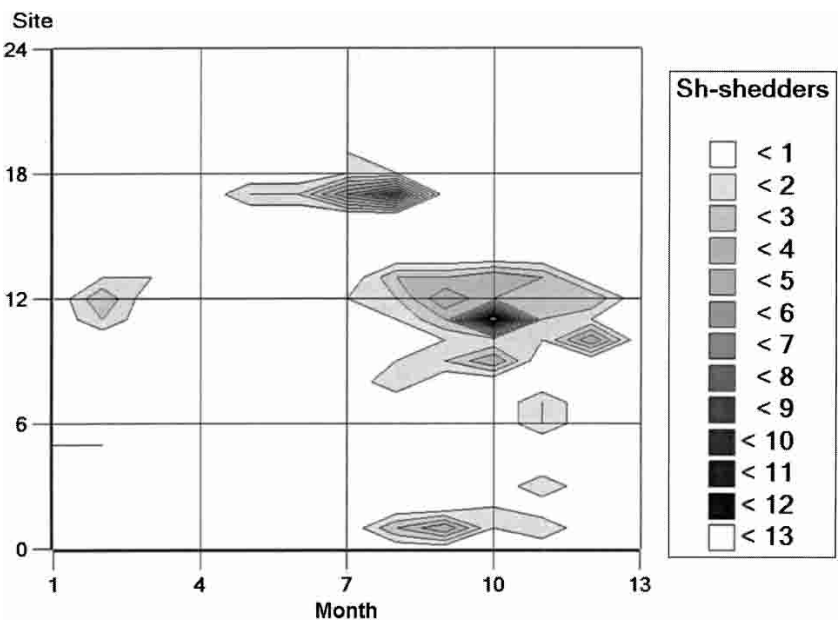

FIGURE 4. Contour plot of the number of Schistosoma haematobium (Sh)-shedding snails at individual study sites in the Msambweni, Kenya area (vertical axis with an arbitrary scale) during the first 13 months of the study (February 2001-March 2002). Contour lines indicate temporal and spatial clustering of positive sampling events, with each having more than a threshold number of S. haematobiumshedding snails either at the same time period at adjacent sampling points or at the same site over contiguous sampling times.

risk, with only a limited number of sites active overall, and only a few sites active at any given time.

Environmental associations. Changes in temperature, turbidity, and $\mathrm{pH}$ were not significantly associated with changes in snail numbers or the percentage of S. haematobium shedding snails.

Vegetation. Vegetation type was significantly associated with presence of several snail species. Both B. nasutus and L. purpureus were positively associated with the presence of water lilies (Nymphaea spp.) $\left(\chi^{2}=57.1\right.$ and 29.1 , respectively, $P<0.001$ ), and negatively with a sedge (Cyperus exaltatus $)\left(\chi^{2}=5.4, P<0.02\right.$ and 12.4, $P<0.0001$, respectively). Bulinus forskalii was positively associated with sedge $\left(\chi^{2}=5.4, P<0.02\right)$ and $M$. tuberculata was negatively associated with grass $\left(\chi^{2}=4.3, P<0.04\right)$. These statistical associations, and particularly the positive association with the presence of lilies, was confirmed in the field by repeated observations of more snails resting on the underside of lily pads than in association with any other vegetation type.

Dissolved ions (conductivity). The highest levels of conductivity were recorded in Kiziamkala and Maridzani ponds; their high conductance was though to be due to their proximity to the ocean. High conductivity was also recorded in the rice field, possibly due to application of agricultural fertilizers. Snail species differ in their tolerance to increasing ion concentrations: high conductivity was negatively correlated with L. purpureus $(\mathrm{r}=-0.53, P<0.0001)$ while correlating positively with $B$. forskalii $(\mathrm{r}=0.18, P<0.01)$. For example, there were no L. purpureus in Kiziamkala pond and only relatively few occurring in the neighboring Maridzani pond (Table 1). However, B. forskalii appeared at these ponds in larger numbers than in all the other habitats. The observed high conductivity in these ponds did not appear to have a limiting effect on B. nasutus. 


\section{DISCUSSION}

Our findings indicate that B. nasutus was the most common snail at the observed water contact sites, and that it was the only evident intermediate host for $S$. haematobium in the study area. At the sites where it was found, apart from $\mathrm{Ki}$ ziamkala pond, $B$. nasutus was sympatric with the larger snail Lanistes purpureus. The spatial distribution of snails was clustered, with few ponds accounting for most of the snails.

In our study area, most B. nasutus snails, and particularly those shedding $S$. haematobium cercariae, were found in Nimbodze pond, the location that was most strongly associated also with clustering of human infection. ${ }^{17}$ Conversely, no $B$. nasutus snails were collected at Mwachiangwa pond, and only a few Lanistes were recovered there. It is likely that chemical, physical, and biologic factors determine the species diversity and snail density to be found in a particular water body at a given period of time. The ecologic conditions for transmission of schistosomiasis in favorable snail habitats can vary considerably from site to site and area to area, even within short distances. ${ }^{25}$ To determine the environmental conditions that may inhibit snail survival or development, further investigations of water composition, e.g., measurements of specific dissolved ions, ${ }^{26,27}$ need to be carried out at these and comparison ponds. In other areas of the Coast Province of Kenya, abundance of $B$. globosus has been linked to water temperature, and rapid growth of $B$. globosus populations has been tied to unseasonable rains during the cooler months. ${ }^{14}$ In our study area, we did not find a significant link between snail abundance and water temperature, perhaps reflecting the narrow range of temperatures observed. ${ }^{10}$

One factor that was significantly associated with snail density was the presence of horizontal vegetation, namely water lilies (Nymphaea spp.). Most snails were observed resting on the underside of the lilies, areas probably rich in oxygen due to photosynthesis. The water lilies also provide egg-laying surfaces, shelter from the sun, and food for many species of snails. For food, the snails feed on the microflora and decaying plant matter of the water lily leaves. ${ }^{28}$ Aquatic macrophytes may also protect snails from predators such as birds. A pitfall that may result in an overemphasis of the importance of water lily leaves is that they are much easier to sample than a dense stand of grass or sedges. For our study area, the presence of water lilies was an effective indicator for the presence of both B. nasutus and L. purpureus. This association deserves further study in other transmission areas. If validated, it is possible that aerial remote sensing, whether by satellite or by less expensive aerial photography, may offer effective means for detection of likely transmission sites.

During long periods of drought, temporary ponds dry up and the snails estivate. ${ }^{29,30}$ As the rains arrive and the ponds fill up, snails are triggered out of estivation and repopulate the water bodies. ${ }^{14}$ However, this effect of rainfall on snails depends on the intensity with which the rains fall; our experience suggests that heavy downpours over a short period of time will fill up snail habitats and have a marked influence on snail populations, while small amounts of rain over a long period of time, which has been the pattern in the study area since 2002, do not result in a sufficient amount of water to re-fill ponds that have dried. Published reports on the length of estivation period do not indicate survival of snails beyond 6-12 months. ${ }^{29-31}$ However, it appears that many of our ponds, including Nimbodze pond (which was had the greatest $B$. nasutus abundance and most frequent $S$. haematobium cercariae production), have been dry for periods that extend beyond the published survival records of aestivated Bulinus or other snails. While survival is likely to be extended in moist areas and under vegetation, the prolonged drought may have drastic long-term impacts on snail populations and cercariae shedding in our study area. This, in turn, may result in changes in human infection patterns and the age distribution of schistosomiasis. ${ }^{17}$

The finding of a large number of snails shedding non-S. haematobium cercariae merits further study because it may be associated with infection of domestic livestock and possibly transmission to humans of zoonotic parasites. Bulinus forskalii is reported to be an intermediate host of Paramphistomum phellerouxi, an amphistome parasite of grazing animals, in Zambia, ${ }^{32}$ and is known to transmit S. bovis. Bulinus globosus has also been associated with transmission of Calicophoron microbothrium, another intestinal amphistome parasite of domestic animals, especially cattle. ${ }^{33}$ A case of Paragonimus-like eggs in humans was reported in Natal Province of South Africa by Proctor and Gregory, ${ }^{34}$ and similar eggs were obtained from cats in Durban area. They were thought to belong to Paragonimus kellicotti, which only rarely infects humans. In these South African studies, M. tuberculata was the only prosobranch snail found in the area, and was therefore suspected to be the intermediate host. Lanistes carinatus is reported to transmit the rat lung-worm Angiostrongylus cantonensis in Egypt. ${ }^{35}$

In Msambweni, further studies will be needed to determine the role of sympatric non-host snails in controlling schistosomiasis transmission by local bulinid snails. The non-host snails may act as biologic control agents for the intermediate hosts by either competing for space and food or by acting as predators. ${ }^{15}$ Marisa cornuarietis has been reported to act as a predator for all stages of Bulinus and Biomphalaria, and has been used as part of schistosomiasis control measures in Puerto Rico and other Caribbean islands. ${ }^{36}$ In addition, some of the non-host snails may protect the intermediate host snails from infection with schistosome miracidia by acting as decoys. Upatham, in a laboratory experiment in St. Lucia, found that two non-host snails, Physa marmorata and Drepanotrema surinamensis could prevent infection of susceptible Biomphalaria glabrata with $S$. mansoni miracidia to a certain degree. ${ }^{37}$

The results of our combined human and snail mapping studies indicate that transmission patterns of urinary schistosomiasis are closely related to the abundance and spatial distribution of host snails, and that travel distance to transmission sites likely plays an important role in determining human risk for infection. For schistosomiasis control programs to be successful, an effective understanding of the spatial and temporal variations in snail densities will be important for determining both the location and timing of control interventions. The use of GIS to integrate remotely-sensed area data on climate and terrain ${ }^{38}$ with other risk markers that can be readily determined at ground level (e.g., aquatic flora) has the potential to improve the effectiveness of site selection for control intervention. However, variability in rainfall patterns, compounded by the ability for the snail intermediate hosts to estivate for several months, complicates the design of predictive transmission models. ${ }^{39,40}$ Although snail abatement combined with population-based drug therapy has the potential to 
strongly suppress transmission, it is likely that successful control of schistosomiasis at Msambweni (and other areas having similar transmission features) will need to be tailored according to the prevailing environmental and weather patterns.

Received October 30, 2003. Accepted for publication December 30, 2003.

Acknowledgments: We thank Anthony Chome, Charles Nganga, Jackson Muinde, Robin Bundi, Idi Masemo, and Joyce Bongo for their invaluable contributions to the field work; Grace Nguma for data entry and management; and Dr. Evelin Grijalva for providing valuable comments. This paper is published with the kind permission of the Director of Medical Services, Ministry of Health, Kenya.

Financial support: This research was supported by the National Institutes of Health under grants AI-45473 (National Institute of Allergy and Infectious Diseases) and TW/ES01543 (Fogarty International Center).

Authors' addresses: H. Curtis Kariuki and Eric M. Muchiri, Division of Vector Borne Diseases, Ministry of Health, PO Box 20750, Nairobi, Kenya, Telephone: 254-20-725-833, Fax: 254-20-720-030, E-mail: schisto@wananchi.com. Julie A. Clennon, Melinda S. Brady, and Uriel Kitron, Division of Epidemiology and Preventive Medicine, Department of Veterinary Pathobiology, University of Illinois, 2001 South Lincoln Avenue, Urbana, IL 61802, Telephone: 217-333-2449, Fax: 217-244-7421, E-mails: jaclenno@uiuc.edu,msbrady@uiuc.edu, and ukitron@uiuc.edu. Robert F. Sturrock, 92 Brennand Road, Dongara, Western Australia, 6525, Australia, Telephone: 61-8-9339-0560, E-mail: sturrock@iprimus.com.au. John H. Ouma, Kenya Medical Research Institute, Mbagathi Road, Nairobi, Kenya, Telephone: 25420-722-541, Fax: 254-20-720-030. Saidi Tosha, Malick Ndzovhu, and Peter Mungai, c/o Case Western Reserve University/Division of Vector-Borne Diseases/Kenya Medical Research Institute FilariasisSchistosomiasis Research Unit, PO Box 8, Msambweni, Kenya, Telephone: 254-40-52267, E-mail: dvbdcwru@wananchi.com. Orit Hoffman and Joseph Hamburger, Helminthology Unit, Hadassah Medical School, Hebrew University of Jerusalem, PO Box 12272, Jerusalem, 91120, Israel, Telephone: 972-2-675-8082, Fax: 972-2-6757425, E-mail: hambu@cc.huji.ac.il. Cara Pellegrini, Department of Medicine, Hospital of the University of Pennsylvania, 3400 Spruce Street, Philadelphia, PA 19104, Telephone: 215-62-2200, E-mail: drpelle3@ yahoo.com. Charles H. King, Center for Global Health and Diseases, Wolstein Research Building, Room 4126, Case Western Reserve University School of Medicine, 10900 Euclid Avenue, Cleveland, OH 44106-7286, Telephone: 216-368-4818, Fax: 216-368-4825, E-mail: chk@po.cwru.edu.

Reprint requests: Charles H. King, Center for Global Health and Diseases, Wolstein Research Building, Room 4126, Case Western Reserve University School of Medicine, 10900 Euclid Avenue, Cleveland, OH 44106-7286.

\section{REFERENCES}

1. King $\mathrm{CH}$, Keating CE, Muruka JF, Ouma JH, Houser H, Siongok TK, Mahmoud AA, 1988. Urinary tract morbidity in schistosomiasis haematobia: associations with age and intensity of infection in an endemic area of Coast Province, Kenya. Am J Trop Med Hyg 39: 361-368.

2. King CH, Lombardi G, Lombardi C, Greenblatt R, Hodder S, Kinyanjui H, Ouma J, Odiambo O, Bryan PJ, Muruka J, Magak P, Weinert D, Mackay W, Ransohoff D, Houser H, Koech D, Siongok TK, Mahmoud AAF, 1988. Chemotherapy-based control of schistosomiasis haematobia. I. Metrifonate versus praziquantel in control of intensity and prevalence of infection. Am J Trop Med Hyg 39: 295-305.

3. Siongok TKA, Ouma JH, Houser HB, Warren KS, 1978. Quantification of infection with Schistosoma haematobium in relation to epidemiology and selective population chemotherapy. II Mass treatment with a single oral dose of metrifonate. $J$ Infect Dis 138: 856-858.

4. Stephenson LS, Latham MC, Kinoti SN, Oduori ML, 1984. Sensitivity and specificity of reagent strips in screening of Kenyan children for Schistosoma haematobium infection. Am J Trop Med Hyg 33: 862-871.
5. Muchiri EM, Ouma JH, King CH, 1996. Dynamics and control of Schistosoma haematobium transmission in Kenya: an overview of the Msambweni Project. Am J Trop Med Hyg 55: 127-134.

6. Highton RB, Choudhry AW, 1974. The cost evaluation of mollusciciding operations on five irrigation schemes in Kenya. East Afr Med J 51: 180-193.

7. Brown DS, Jelnes JE, Kinoti GK, Ouma J, 1981. Distribution in Kenya of intermediate hosts of Schistosoma. Trop Geogr Med 33: 95-103.

8. Sturrock RF, 1965. Studies on the biology of Biomphalaria angulosa Mandahl-Barth and on its ability to act as an intermediate host of Schistosoma mansoni. Ann Trop Med Parasitol 59: $1-9$.

9. Joubert PH, Pretorius SJ, de Kock KN, van Eeden JA, 1986. Survival of Bulinus africanus (Krauss), Bulinus globosus (Morelet), and Biomphalaria pfeifferi (Krauss) at constant high temperatures. S Afr J Zool 21: 85-88.

10. Cridland CC, 1955. The experimental infection of several species of African freshwater snails with Schistosoma mansoni and $S$. haematobium. J Trop Med Hyg 58: 1-11.

11. Southgate VR, Knowles RJ, 1977. On the intermediate hosts of Schistosoma haematobium from Western Kenya. Trans $R$ Soc Trop Med Hyg 71: 82-83.

12. Mandahl-Barth G, 1958. The Intermediate Hosts of Schistosoma: African Biomphalaria and Bulinus. Geneva: World Health Organization.

13. O'Keefe JH, 1985. Population biology of the freshwater snail Bulinus globosus on the Kenya coast: I. Population fluctuations in relation to climate. J Appl Ecol 22: 73-84.

14. Sturrock RF, Kinyanjui H, Thiongo FW, Tosha S, Ouma JH, King CH, Koech D, Siongok TK, Mahmoud AA, 1990. Chemotherapy-based control of schistosomiasis haematobia. 3. Snail studies monitoring the effect of chemotherapy on transmission in the Msambweni area, Kenya. Trans R Soc Trop Med Hyg 84: 257-261.

15. Ndela B, Madsen H, 2001. Laboratory and quasi-field studies on interspecific competition between Bulinus globosus and $B$. tropicus (Gastropoda: Planorbidae). Afr J Aquatic Sci 26: 1721.

16. Clennon JA, King $\mathrm{CH}$, Muchiri EM, Kariuki HC, Ouma JH, Mungai P, Kitron U, 2004. Spatial patterns of urinary schistosomiasis infection in a highly endemic area of coastal Kenya. Am J Trop Med Hyg 70: 443-448.

17. el Kholy H, Arap Siongok TK, Koech D, Sturrock RF, Houser H, King CH, Mahmoud AA, 1989. Effects of borehole wells on water utilization in Schistosoma haematobium endemic communities in Coast Province, Kenya. Am J Trop Med Hyg 41 : 212-219.

18. Ouma JH, Sturrock RF, Klumpp RK, Kariuki HC, 1989. A comparative evaluation of snail sampling and cercariometry to detect Schistosoma mansoni transmission in a large-scale, longitudinal field-study in Machakos, Kenya. Parasitology 99: 349355.

19. Rollinson D, Stothard JR, Southgate VR, 2001. Interactions between intermediate snail hosts of the genus Bulinus and schistosomes of the Schistosoma haematobium group. Parasitology 123 (Suppl): S245-S260.

20. Frandsen F, Christensen NO, 1984. An introductory guide to the identification of cercariae from African freshwater snails with special reference to cercariae of trematode species of medical and veterinary importance. Acta Trop 41: 181-202.

21. Chen D, Getis A, 1998. Point Pattern Analysis. San Diego, CA: Department of Geography, San Diego State University.

22. Ripley BD, 1981. Spatial Statistics. New York: John Wiley and Sons.

23. Getis A, 1984. Interaction modeling using second-order analysis. Environ Planning A 16: 173-183.

24. Getis A, Ord JK, 1996. Local spatial statistics: an overview. Longley P, Batty M, eds. Spatial Analysis: Modeling in a GIS Environment. Cambridge, United Kingdom: Geoinformation International, 261-277.

25. Pesigan TP, Hairston NG, Jauregui JJ, Garcia EG, Santos AT, Santos BC, Besa AA, 1958. Studies on Schistosoma japonicum infection in the Philippines. 2. The molluscan host. Bull World Health Organ 18: 481-578. 
26. James DR, Morgan E, Candy DJ, 1990. Changes in ionic composition of media during culture of Bulinus tropicus and the relationship between ion concentrations and inhibition of growth and egg-laying. J Appl Ecol 27: 30-40.

27. Donnelly FA, Appleton CC, Schutte CH, 1983. The influence of salinity on certain aspects of the biology of Bulinus (Physopsis) africanus. Int J Parasitol 13: 539-545.

28. O'Keefe JH, 1985. Population biology of the freshwater snail Bulinus globosus on the Kenya coast II. Feeding and density effects on population parameters. $J$ Appl Ecol 22: 85-90.

29. Webbe G, Msangi AS, 1958. Observations on three species of Bulinus on the east coast of Africa. Ann Trop Med Parasitol 52: 302-314.

30. McCullough FS, Eyakuze VM, Msinde J, Nditi H, 1968. Water resources and bilharziasis transmission in the Misungwi area, Mwanza District, north-west Tanzania. East Afr Med J 45: 295308.

31. Pringle G, Otieno LH, Chimtawi MB, 1971. Notes on the morphology, susceptibility to Schistosoma haematobium and genetic relationships of Bulinus (Physopsis) globosus globosus and B.(P.) nasutus nasutus from north-eastern Tanzania. Ann Trop Med Parasitol 65: 211-219.

32. Brown DS, 1994. Freshwater Snails of Africa and Their Medical Importance. London: Taylor \& Francis Ltd.

33. Wright CA, Rollinson D, Goll PH, 1979. Parasites in Bulinus senegalensis (Mollusca: Planorbidae) and their detection. Parasitology 79: 95-105.

34. Proctor EM, Gregory MA, 1974. An ultrastructural study of ova of Paragonimus species from human and cat faeces. $S$ Afr Med J 48: 1947-1948.

35. Yousif F, Ibrahim A, 1978. The first record of Angiostrongylus cantonensis from Egypt. Z Parasitenkd 56: 73-80.

36. Jordan P, Christie JD, Unrau GO, 1980. Schistosomiasis transmission with particular reference to possible ecological and biological methods of control. A review. Acta Trop 37: 95-135.

37. Upatham ES, 1972. Interference by unsusceptible aquatic animals with the capacity of the miracidia of Schistosoma mansoni Sambon to infect Biomphalaria glabrata (Say) under fieldsimulated conditions in St. Lucia, West Indies. J Helminthol 46: 277-283.

38. Malone JB, Huh OK, Fehler DP, Wilson PA, Wilensky DE, Holmes RA, Elmagdoub AI, 1994. Temperature data from satellite imagery and the distribution of schistosomiasis in Egypt. Am J Trop Med Hyg 50: 714-722.

39. Barbour AD, 1996. Modeling the transmission of schistosomiasis: an introductory view. Am J Trop Med Hyg 55: 135-143.

40. Lee KL, Lewis ER, 1976. Delay time models of population dynamics with application to schistosomiasis control. IEEE Trans Biomed Eng 23: 225-233. 